\title{
Ressonâncias do romantismo e da literatura fantástica na psicanálise
}

\author{
Fabiano Chagas Rabêlo ${ }^{a *}$ (1) \\ Reginaldo Rodrigues Dias ${ }^{\mathrm{a}}$ (1) \\ Karla Patrícia Holanda Martins ${ }^{\mathrm{b}}$ (]) \\ Karl Erik Schollhammerc (i) \\ aUniversidade Federal do Delta do Parnaíba, PI, Brasil \\ 'Universidade Federal do Ceará, CE, Brasil \\ 'Pontifícia Universidade Católica do Rio de Janeiro, RJ, Brasil
}

\begin{abstract}
Resumo: Mapeiam-se os processos históricos, estéticos e epistêmicos dos séculos XVIII e XIX que associam romantismo, literatura fantástica e psicanálise. Defende-se que o fantástico constitui um importante vetor por meio do qual elementos do romantismo foram incorporados ao modelo psicanalítico de aparelho psíquico. Parte-se da perspectiva de que a assimilação da influência romântica realizou-se de forma seletiva e criativa. Destacam-se alguns pontos de tensões e compromissos entre romantismo e o iluminismo, que foram retomados e transformados pelo fantástico e a psicanálise: as temáticas do amor, da loucura, da sexualidade, das superstições e dos mitos; o questionamento da relação entre o real e suas representações e entre pensamento e consciência; e a valorização do uso retórico da ironia. Aponta-se a abordagem psicanalítica do infamiliar (Unheimliche) como o momento mais sensível dessa interlocução.
\end{abstract}

Palavras-chave: romantismo, literatura fantástica, psicanálise, Unheimliche.

\section{Introdução}

Este artigo comenta os vínculos que se estabeleceram entre literatura fantástica, psicanálise e romantismo, entendendo o último como um elo estratégico entre os dois primeiros. Parte-se da premissa de que a partir da tradição instaurada pelo romantismo é possível problematizar de forma mais aprofundada algumas temáticas que posteriormente se desenvolveram no âmbito da literatura fantástica e da psicanálise.

Vale a pena lembrar que a origem da literatura fantástica situa-se no início do século XIX (Batalha, 2012; Ceserani, 1999; Todorov, 2012), mesmo período do auge do romantismo na Europa (Palma, Chiarini, \& Teixeira, 2013). O ápice do fantástico, por sua vez, aconteceu no final do mesmo século (Calvino, 2004; Ceserani, 1999), coincidindo com a pré-história da psicanálise (Gay, 1989). Sugere-se então, como hipótese a ser investigada, que a literatura fantástica constituiu um importante vetor por meio do qual elementos da tradição romântica foram incorporados ao modelo psicanalítico de aparelho psíquico.

Deve-se esclarecer que nos dois casos a assimilação da influência romântica realizou-se de forma seletiva e criativa. O fantástico e a psicanálise não só incorporaram traços específicos e pontuais do romantismo como também

*Endereço para correspondência: fabrabelo@gmail.com acrescentaram neles transformações significativas (Carvalho, 1989; Ceserani, 1999), de forma que não se trata, aqui, de dirimir a originalidade de um ou de outro, mas de avaliar a complexa rede de influências que os liga ao romantismo. Daí o destaque dado ao ambiente cultural, histórico, geográfico e linguístico que propiciou tais mediações.

Entende-se por romantismo o movimento cultural, ideológico e estético que surgiu no final do século XVIII, inicialmente na Europa, estendendo-se posteriormente para outros países (Palma et al., 2013). Ainda que seu apogeu tenha acontecido no início do século XIX, sua influência é perceptível ainda hoje não só na arte e na literatura, mas também na ciência e nos costumes (Löwy \& Sayre, 1995).

O romantismo despontou como um contraponto ao iluminismo, ao racionalismo e ao classicismo. Sua crítica, contudo, não nega o projeto da modernidade em sua totalidade, uma vez que os românticos assimilaram alguns de seus traços e premissas, o que contribuiu para a formação de uma concepção de subjetividade que se tornou amplamente difundida na contemporaneidade (Löwy \& Sayre, 1995). A principal marca do romantismo está, portanto, na valorização do singular, do radical e da exceção (Löwy \& Sayre, 1995) ou, como sugere Loureiro (2020a), do estilo.

O fantástico, a seu turno, é definido como um modo de fazer literatura que engendra uma ambiência 
soturna, que leva o leitor, de forma labiríntica e sorrateira, a se confrontar com um fato aparentemente sobrenatural e extraordinário (Calvino, 2006; Casares, 2013). Tal expediente, no entanto, está fortemente alicerçado em uma narrativa racional e lógica que mimetiza o cotidiano para, em seu desfecho, produzir uma ruptura com a expectativa de linearidade que o próprio texto acalenta (Roas, 2014). Tal arranjo visa desencadear uma vacilação na confiança do leitor acerca da consistência de sua apreensão do mundo e do sentimento de familiaridade em relação às coisas que o cercam. A divisão subjetiva instaurada por essa arquitetura textual é, para muitos teóricos, o traço distintivo da literatura fantástica (Roas, 2014; Todorov, 2012).

A psicanálise pode ser descrita como: (1) um procedimento de investigação dos processos psíquicos apoiado na hipótese do inconsciente; (2) uma modalidade de tratamento dos distúrbios neuróticos; e (3) uma disciplina estabelecida pela reunião das informações dessas duas primeiras linhas de trabalho (Freud, 1922/1999). Ela surgiu da dignificação de práticas e temas considerados marginais pela medicina do final do século XIX, que cultivava o ideal de se valer exclusivamente de procedimentos químicos e fisicalistas (Freud, 1924/1999, 1925/1999). Nesse contexto, o tratamento psíquico (Freud, 1890/1997), que se fundamentava na fala, era tido pela ortodoxia médica como um método de intervenção desprovido de embasamento científico, vinculado à prática de impostores e supersticiosos.

Freud (1890/1997, 1904/1997) propôs então o reconhecimento da materialidade da palavra como um instrumento cientificamente orientado de investigação e intervenção terapêutica. Daí o seu interesse pela hipnose, a sugestão e o vínculo entre médico e paciente como recursos para o tratamento de algumas modalidades de sofrimento psíquico que se encontravam fora do alcance da influência da medicina tradicional. A Interpretação dos sonhos, na virada do século XX, constitui o marco do surgimento da psicanálise, quando ocorre $\mathrm{o}$ abandono da hipnose e a adoção da associação livre (Freud, 1922/1999).

Do exposto, sublinha-se que o intuito deste trabalho é desenhar um mapa dos pontos de convergência e discrepâncias que há entre romantismo, literatura fantástica e psicanálise, a fim de esclarecer a apropriação da herança dos dois primeiros pela última. Trata-se de uma investigação teórica, qualitativa, bibliográfica, interdisciplinar, em formato de ensaio.

\section{Romantismo}

$\mathrm{O}$ adjetivo romântico surgiu em referência às histórias de cavalarias, gênero amplamente difundido durante a Idade Média. No século XVII, na Inglaterra, esse termo adquiriu conotação pejorativa, passando a indicar uma atitude excessivamente imaginativa ou emocional (Löwy \& Sayre, 1995; Palma et al., 2013). Posteriormente, a palavra romantismo, já substantivada, passou a designar o movimento cultural e artístico que surgiu de forma "semelhante, independente e sincrônica" (Löwy \& Sayre, 1995, p. 80) na Alemanha, Inglaterra e França no final do século XVIII e que se estendeu pelas primeiras décadas do século seguinte para outras regiões.

Deve-se ressaltar que tal cronologia suscita divergências. Muitos autores localizam o início do romantismo em um período anterior; outros propõem o termo pré-romântico para se referir às obras de transição precursoras desse movimento (Löwy \& Sayre, 1995). Há ainda quem defenda o prolongamento do romantismo - ou de traços dele - para além da primeira metade do século XIX (Mann, 1929/1991).

Salientou-se na introdução que a marca principal do romantismo é a intenção de estabelecer um contraponto ao iluminismo. Nesse sentido, ele não deve ser tomado por um movimento obscurantista, retrógrado ou conservador, haja vista que sua crítica incide de modo seletivo sobre alguns traços da modernidade, almejando alcançar daí uma concepção expandida de razão. Nas palavras de T. Mann (1875-1955) (1929/1991), referindo-se ao filósofo F. W. Nietzsche (1844-1900), o romantismo constituiu simultaneamente um movimento de reação e de avanço em relação ao iluminismo e ao racionalismo, no sentido de manutenção de seus fundamentos e correção de suas imperfeições.

Os autores românticos resgataram elementos da tradição popular oral, incorporando à escrita traços de uma musicalidade e coloquialidade (Carpeaux, 2014; Loureiro, 2002a). Daí o interesse pelas sagas europeias medievais, que passaram a ocupar o lugar que os mitos gregos possuíam no classicismo.

Outra marca importante do romantismo é a preocupação em superar as fronteiras entre gêneros literários e modalidades de produção artística, o que contribuiu para um diálogo mais fluído entre artes plásticas, música e literatura, além de uma confluência mais acentuada entre prosa e poesia.

Os românticos se opunham à estética renascentista, que almejava um ideal de beleza greco-romano, calcado na boa forma e na proporcionalidade das medidas. Da crítica ao modelo de beleza clássico e à razão iluminista surgiu o interesse pelo imprevisível e o incomensurável, encarnado, sobretudo, na contemplação à natureza, o que desencadeou uma importante mudança na forma de se conceber a estética: o belo, que ocupava o lugar de meta da produção artística, cede lugar ao sublime. Enquanto aquele almeja apaziguar o espírito por meio de uma relação harmoniosa com a obra, este busca inquietar, proporcionando uma abertura para o transcendente e o inefável (Cattapan, 2019; Trias, 2005).

Sobre esse ponto, considera-se paradigmática a analogia entre os impulsos subjetivos e as forças da natureza, tal como sustentado pelo movimento Sturm und Drang - em português, tempestade e ímpeto -, que ocorreu na Alemanha no final do século XVIII, do qual F. Schiller (1759-1805) e J. W. Goethe (1749-1832) 
fizeram parte. Para Duarte (2004) e Loureiro (2002a), tal movimento teve forte impacto na obra de Freud.

Apesar dessas diretrizes, o romantismo não possuía um projeto coeso e rígido, o que explica seu amplo leque de inflexões geográficas e linguísticas. Um interessante exemplo disso é o ultrarromantismo, que influenciou a literatura fantástica portuguesa e brasileira na segunda metade do século XIX (Matangrano \& Tavares, 2018).

Feitas essas considerações mais gerais acerca do romantismo, elencam-se a seguir alguns dos principais traços da modernidade contestados pelos românticos.

Inicialmente, é importante destacar a preocupação com o desencantamento da vida pela ciência. Até a Idade Média, o mundo era, para o homem comum, habitado por forças sobrenaturais, que constantemente interferiam no cotidiano e determinavam o curso de seu destino. Sabe-se que a passagem do pensamento religioso e mágico para o racional e concreto transcorreu de forma lenta, gradual e incompleta, sendo esse processo perpassado por conflitos, compromissos e retrocessos.

Um exemplo disso é a transição de um modelo de mundo aristotélico, fechado e finito, que orientava o pensamento na idade média, para o de universo aberto e infinito (Koyré, 2006). Tal fato, contudo, não erradicou por completo as concepções pré-iluministas, que migraram para outro patamar do saber - o informal, assistemático, vinculado ao senso-comum - e daí continuaram a influenciar o julgamento das pessoas (Ceserani, 1999). O romantismo buscou reabilitar alguns saberes menosprezados pelos racionalistas a partir de uma perspectiva estética e filosófica. Algumas décadas depois, a psicanálise seguiu o mesmo caminho da perspectiva da clínica (Loureiro, 2002a).

Sobressaiu entre os românticos o interesse pelos mitos, considerados por eles um elo entre religião, história, poesia e linguagem: um reservatório de símbolos e alegorias, uma nova via, dessa vez de caráter laico, de acesso ao sagrado (Löwy \& Sayre, 1995).

Outro ponto criticado pelos românticos é a abordagem cada vez mais quantitativa e mecânica dos fenômenos da natureza. A partir da Revolução Industrial, a natureza passou a ser vista como uma matéria-prima a ser explorada e precificada, tal como o tempo, a energia e a mão de obra dos trabalhadores (Löwy \& Sayre, 1995). O romantismo respondeu a essa situação com o elogio à dinâmica do orgânico, que contrastava com a descrição maquínica do corpo humano adotada pelas ciências modernas: a física, a fisiologia e a anatomia.

As forças da natureza passaram então a ser valorizadas em função de seu caráter misterioso, insondável e incontrolável (Loureiro, 2002a). Um desdobramento importante desse projeto é a defesa da unidade do ser diante da ameaça iminente de sua fragmentação, de onde se explica a preferência por uma explicação monista e holística do mundo e a recusa de uma objetividade externa absoluta (Duarte, 2004).
Nesse contexto, a pulsão (Trieb), na condição de um impulso natural à criação, tornou-se a força motriz da produção artística (Duarte, 2004). A obra de arte passou a ser contemplada por aquilo que ela apresenta de singular e irredutível. Seu padrão de referência deixou de ser a mimese - a imitação da realidade - e a boa forma. Originalidade, intensidade e unidade tornaram-se uma tríade inseparável do projeto artístico romântico. Daí a importância dada à questão do estilo (Loureiro, 2002a).

Os românticos não se opunham a uma abordagem lógica, metódica e concreta do mundo, mas questionavam uma ideia de razão essencialista e unívoca (Loureiro, 2002a). Nas artes, o esforço de ampliação dos limites da razão materializou-se no exercício e na defesa da liberdade criativa. Na literatura, tal tendência pode ser percebida na assunção cada vez mais frequente do monólogo interior e da perspectiva de um narrador não onisciente (Löwy \& Sayre, 1995), o que é fundamental para a conformação da literatura fantástica (Ceserani, 1999).

Nesse contexto, o amor e a loucura se consolidaram como temas privilegiados, na medida em que ambos evidenciam um modo singular e diferenciado de articulação entre representação, afeto e pensamento. $\mathrm{O}$ amor, principalmente, passou a ser intensamente valorizado, sendo elevado à condição de uma verdade individual, interna e absoluta. Criou-se daí um ideal de vida - a busca da felicidade por meio da fusão sexual e espiritual com outro ser - que, apesar de amplamente criticado, ainda desempenha hoje significativa influência social, cultural e artística.

A loucura, por sua vez, passou a ser valorizada como uma resposta ao mistério da criatividade artística (Löwy \& Sayre, 1995). Vale lembrar que, na Idade Clássica, a loucura é gradualmente destituída do lugar de verdade e de sagrado ao qual esteve identificada. Ao ser transposta à categoria de doença mental, ela se torna objeto dos cuidados da medicina moderna e, posteriormente, da psiquiatria (Foucault, 1978, 1999). O louco passa, então, a ser visto como alguém destituído de razão, incapaz de tomar suas próprias decisões.

Na contramão desse processo de desautorização da loucura, os românticos buscaram tratar o louco como uma pessoa que possui racionalidade própria e que, a seu modo, é capaz de expressar uma genialidade inventiva.

$\mathrm{Na}$ esteira da renovação do interesse pelo estilo gótico, os românticos passaram a enaltecer a noite e as sombras. É importante lembrar que a Era Medieval era designada pelos iluministas como a idade das trevas, sendo a luz o símbolo absoluto da razão (Loureiro, 2002a; Löwy \& Sayre, 1995). Por conseguinte, a utilização da figura da noite remete à intenção de resgatar o que havia sido abandonado pelo projeto iluminista. Esse mote inspirou uma tendência do romantismo, especialmente em sua vertente mais tardia, que adotou uma atitude mais pessimista diante do projeto civilizatório da razão instrumentalizada encampado pela Revolução Industrial. 
Tal fato foi de importância ímpar para o desenvolvimento do projeto literário fantástico e da clínica psicanalítica. Doravante, o sonho ganha espaço como expressão de uma atividade mental criativa e autônoma, que faz frente a uma concepção de pensamento racional identificada à consciência. Também ganha destaque o uso da ironia como estratégia retórica (Duarte, 2004; Loureiro, 2002a).

Parte-se da perspectiva de que a ironia romântica constituiu uma atitude diante da razão que, no entanto, não prescinde dela: ela se vale de um discurso fundamentado na racionalidade, centrado em um pensamento supostamente translúcido e reflexivo, para desbaratá-lo do seu interior, com suas próprias armas e, desse modo, fomentar uma forma de racionalidade mais ampla (Kierkegaard, 1976).

Para concluir esse tópico, chama-se atenção para a crítica romântica ao modelo de Estado moderno. Como resposta ao período de convulsão social impulsionado pela Revolução Francesa, a reivindicação por um novo projeto político tornou-se um ponto relevante entre os românticos (Rodrigues, 2007), que se empenharam em produzir novas formas de laço comunitário (Löwy \& Sayre, 1995). Essa meta, por sua vez, só poderia ser alcançada por meio de um processo mais amplo de formação (Bildung), que tornaria o indivíduo apto à fruição, à criação artística e ao engajamento em relações sociais eticamente mais justas. A urgência em produzir relações de trocas mais genuínas incentivou o interesse por formas de sociabilidade arcaicas. Com isso, o projeto social e político romântico assumiu um traço nostálgico e utópico.

Vejamos então como as questões que foram apontadas durante esse tópico comparecem na literatura fantástica e na psicanálise.

\section{A literatura fantástica}

Como dito na introdução, os últimos momentos do romantismo, em sua fase mais sombria, coincidem com o surgimento da literatura fantástica. Segundo Rancière (2009), durante o século XIX houve uma mudança radical do regime estético, caracterizado por uma transformação na forma de se conceber a relação entre imagem e representação, o que culminou em uma tendência de fragmentação das estratégias narrativas, do processo de construção dos personagens e da própria temporalidade do enredo.

Para Ceserani (1999), o traço principal da literatura que se desenvolveu nesse período - notadamente a fantástica - é a intenção de explicitar e problematizar os procedimentos narrativos e os mecanismos da ficção em uma espécie de metanarrativa. Essa tendência pode ser constatada na ênfase na adoção da perspectiva em primeira pessoa, na busca pela implicação afetiva do leitor, na construção de jogos de imagens e na ampla utilização de hiatos e sobredeterminações de sentido. $\mathrm{O}$ autor sublinha ainda algumas experimentações que surgiram no interior da literatura fantástica: a representação subjetiva do tempo, a valorização das incoerências e hesitações dos personagens e o destaque dado aos sonhos, fantasias e visões.

Nesse contexto, pode-se dizer que os textos de E. T. A. Hoffmann (1776-1822) constituem um elo estratégico entre o romantismo, a literatura fantástica e a psicanálise. Deve-se, contudo, registrar outros autores que o antecederam, mas que não produziram o mesmo impacto: W. Walpole (1717-1797), J. Cazotte (1719-1792) e J. Potocki (1761-1815) (Batalha, 2003). Todos eles, em maior ou em menor medida, têm em comum a influência do estilo gótico, de onde se destaca, além da predileção pelos excessos e contrastes, o esmero na criação de uma ambiência obscura, que simulava, de forma mais ou menos estereotipada, a sensação de estar em um prédio de arquitetura medieval (Ceserani, 1999).

Tal literatura teve, entretanto, vida curta. Não tardou para que, ainda no século XVIII, o interesse por castelos, igrejas e catedrais fosse suplantado por outras formas de criar uma atmosfera de medo e tensão. De início, as figuras demoníacas, fantasmáticas e vampirescas se prestaram a essa função. Gradualmente, tais temáticas, sem desaparecer por completo, deram lugar a estratégias mais corriqueiras e concretas de alusão ao sobrenatural. Para Calvino (2004), o fantástico visionário do início do século XIX foi paulatinamente substituído pelo fantástico cotidiano, que predominou no final desse século.

Constata-se, nesse percurso - do gótico ao fantástico -, um deslocamento: de uma arquitetura em sentido figurativo, que explora os detalhes da estrutura dos prédios medievais como uma metáfora da alma humana, para uma arquitetura em sentido estendido, compreendida aqui como a realização de uma conjuntura psíquica específica, delimitada pela modulação do afeto de angústia e pela evocação do sentimento do infamiliar (Unheimliche) (Freud, 1919/2019).

Ceserani (1999) situa ainda como temática recorrente na literatura fantástica o questionamento do ideal de amor romântico: por um lado, o elogio ao amor como a união perfeita e absoluta entre corpos e almas; de outro, o reconhecimento da impossibilidade de se alcançar tal unidade. Decorre daí uma atitude de idealização do amor, que passa a ser intensamente almejado, mas apenas indiretamente, em sua forma sublimada. Como resultado, percebe-se uma forte ênfase nos componentes eróticos, ao mesmo tempo em que sua expressão é restrita aos seus substitutos estéticos. Com isso, fortaleceu-se o interesse pelos aspectos mais desviantes e sombrios da sexualidade (Rodrigues, 2007), que, não obstante, continuaram a ocupar uma posição encoberta e marginalizada. Tais componentes são, por sua vez, fartamente explorados pela literatura fantástica (Ceserani, 1999), que se preocupou em evidenciar a face mais obscura do amor, em especial na sua relação com a morte. Pode-se dizer, daí, que a literatura fantástica, assim como a obra do Marquês de Sade (1740-1814), é 
fruto dessa conjuntura sociocultural (Rodrigues, 2007), que posteriormente também influenciou a psicanálise.

Siebers (1984) enfatiza outro aspecto da herança romântica assimilada pelo fantástico: a atração pelo sobrenatural e pelas superstições. Diferentemente da filosofia iluminista, que desqualificou esses temas, reduzindo-os à condição de resíduo de uma visão de mundo pré-racionalista; o romantismo adotou uma atitude de estetização dos mitos e crenças populares. Tal abordagem é radicalizada no âmbito da literatura fantástica, cujos textos não se cansam de indagar os limites da verdade e da possibilidade de acesso à realidade. Para isso, os autores fantásticos românticos levaram em consideração não só as fontes eruditas e formais, mas também o senso comum e o saber popular. Da tensão entre esses campos, criou-se uma zona crepuscular onde o natural e o sobrenatural se enodam e se confundem.

Esse interesse, por sua vez, refletiu-se no próprio procedimento narrativo. Para Siebers (1984), o problema da superstição não se resolve por uma escolha intencional entre uma abordagem racional e materialista, de um lado, e outra, transcendental e sobrenatural. Segundo ele, há uma estratégia na forma de contar histórias fantásticas que entrelaça de forma sutil as crenças mais profundas do leitor com as do personagem/ narrador, construindo um contraste com uma atitude cética e factual predominante na narrativa. Com isso, faz-se um apelo à confiança e ao julgamento crítico do leitor, ao mesmo tempo em que o texto lhe insinua uma série de interpretações contraditórias e excludentes. Daí é tecido um conjunto de circunvoluções, a partir das quais o sobrenatural se insinua como uma realidade assombrosamente verossímil. O leitor então é atraído por algo que racionalmente julga não existir e que refuta, mas cuja realidade intimamente acalenta.

Apesar de apontar para essa complexa dialética, Siebers põe no centro de sua avaliação do fantástico romântico uma análise socioantropológica. Para ele, as superstições sempre põem em jogo relações recíprocas de exclusão e inclusão, de estigmatização e identificação, de legitimação e desautorização de discursos e atores sociais. Mesmo sem concordar com a amplitude da conclusão de Siebers, é razoável referendar parcialmente seu raciocínio, reconhecendo como forte marca da literatura fantástica a produção de uma tensa coalescência entre realidade psíquica e social. Ou seja, na literatura fantástica, a fantasia é uma forma de se conjurar e questionar a realidade política e social.

Siebers (1984) sublinha ainda o uso da ironia como outro traço de relevo da herança romântica na literatura fantástica. Aqui, no entanto, a ironia adquire uma forma específica: a identificação com a figura do excluído, do louco, do marginal e do criminoso. De acordo com o autor, predomina no fantástico romântico a tendência de desqualificar o personagem-narrador e, eventualmente, o próprio escritor, o que pode levar a riscos à sua saúde.
Acredita-se que tal hipótese, com alguma variação, já está presente no texto do psicanalista O. Rank (18841939) sobre o duplo. Sem se referir diretamente ao fantástico ou ao romantismo, mas citando vários escritores identificados a esses dois movimentos, como é o caso de Hoffmann, Poe e Maupassant, Rank (1914) verifica uma relação causal entre os traços patológicos dos escritores e a exploração literária da temática do duplo. Para Siebers (1984) haveria uma correspondência análoga entre a estratégia irônica de autodepreciação do narrador e uma tendência de fragilização psíquica do escritor.

Mesmo sem aderir aos argumentos de Siebers e Rank, considera-se interessante explorá-los da perspectiva da apropriação da temática da melancolia pela literatura fantástica. Ou seja, toma-se aqui a autodepreciação irônica antes como uma estratégia estética, e não necessariamente como a expressão de um niilismo social ou uma tendência mórbida.

Partindo do comentário dos textos de T. Gautier (1811-1872) e E. T. A. Hoffmann, autores reconhecidos por sua vinculação ao fantástico, Cantagrel (2004) discute a relação entre romantismo e melancolia. Redefinida pela psicopatologia médica do final do século XVIII como uma forma de loucura atenuada, a etiologia da melancolia passa a ser explicada a partir dos efeitos das paixões e da imaginação no cérebro. Em função desses novos agentes provocadores e relações de causalidade, houve então uma aproximação entre as patologias mentais e os estados de normalidade, que passaram a se combinar, constituindo uma espécie de contínuo. Ganhou força nesse momento a oposição diagnóstica entre melancolia e mania: enquanto nesta sobressai o curso errático e intensificado dos pensamentos e a dificuldade em consolidar conexões ideativas, naquela prepondera ideias fixas delirantes e o humor rebaixado.

De acordo com Cantagrel (2004), Hoffmann se valeu dessa definição médica para interrogar a própria condição humana e a natureza criativa do artista. $\mathrm{O}$ autor elenca então alguns temas que sobressaem na obra de Hoffmann: as ambivalências da marginalidade, a confusão entre exterior e interior, o vínculo entre doença e verdade, as alternâncias cíclicas entre impotência e criação, e a incongruência entre amor e realidade.

Todos esses elementos estão presentes no conto mais célebre de Hoffmann (1817/2015), "O homem de areia", que despertou o interesse de Rank (1914) e, posteriormente, de Freud (1919/2019). Nessa história, o protagonista apaixona-se inadvertidamente por uma boneca, que acredita ser humana. $O$ texto está organizado em cartas, que são trocadas entre Nathanael, o personagem principal, e dois outros interlocutores: sua noiva e o irmão dela. Na medida em que a narrativa avança, percebe-se a deterioração da saúde e do entendimento de Nathanael, ao mesmo tempo em que sua retórica permanece lúcida e precisa, pelo menos até sua conclusão. Mesmo o improvável enamoramento e a bizarra figura do homem de areia 
e de seus avatares são descritos de forma bastante verossímil e cotidiana, o que contribui para a captura do leitor na trama. A experiência de angústia do leitor é construída de pouco em pouco, pelo acúmulo de uma sequência de detalhes aparentemente corriqueiros e banais.

Entende-se, portanto, que a obra de Hoffmann e o conceito de Unheimliche condensam essa rede de influências que, do romantismo, perpassam a literatura fantástica até chegar à psicanálise. Cabe agora apontar como essa influência se materializa na metapsicologia freudiana.

\section{Psicanálise}

Identifica-se como o principal componente da herança romântica que atravessa tanto o fantástico como a psicanálise o interesse pelos ditos desvios, distorções e perversões da sexualidade (Ceserani, 1999). Se, no romantismo, tais elementos encontravam-se intensamente mobilizados, sua expressão estava condicionada à realização de um ideal de amor por uma via estética. $\mathrm{O}$ traço de desmesura e desproporcionalidade que as expressões artísticas românticas assumem evidencia que uma relação peculiar com um objeto com características próprias - que não podem ser qualificadas como harmônicas - está colocada em questão.

$\mathrm{Na}$ literatura fantástica, esses elementos da sexualidade que estão no cerne, mas não corroboram o ideal de amor romântico, ganham evidência. Porém, nesse contexto, seu reconhecimento se presta a uma função bastante específica: a mobilização do desejo, a modulação da angústia e a produção da surpresa do leitor. Um exemplo disso é o laço amoroso, tão improvável como impetuoso, que une Nathanael à boneca Olímpia (Hoffmann, 1817/2015). O texto de Hoffmann não é um caso isolado. Indicam-se os seguintes textos que exploram a conexão entre sexo e angústia: "A morta enamorada", de T. Gautier (1836/1999), "Ligeia”, de E. A. Poe (1838/2006) e "A morta", de G. de Maupassant (1887/2015).

A psicanálise, por sua vez, nasce da constatação de que esses componentes desviantes da sexualidade são uma parte importante e significativa da constituição psíquica humana. Ao relacionar tais elementos com a etiologia da neurose, Freud (1905/1997b) estabeleceu os fundamentos para o tratamento psicanalítico das doenças nervosas. Para isso, ele constata que é necessário trabalhar com a angústia, tomando-a como fator estratégico associado à resistência psíquica, que surge modificada em cada etapa do tratamento. Logo não faz parte da proposta psicanalítica produzir deliberadamente situações de angústia, mas de acolhêlas e modulá-las para que as condições de realização do tratamento analítico sejam produzidas.

O caráter aparentemente irracional, despropositado e infantil da angústia suscitada pelas narrativas fantásticas são, por assim dizer, a outra face da moeda da teoria do desenvolvimento psicossexual (Freud, 1905/1997b). O que e está em jogo nessa proposição é a ideia de que nem o amor nem a sexualidade são categorias imanentes, congênitas, unitárias e homogêneas. A correspondência entre as práticas perversas do adulto e as idiossincrasias da infância corrobora a tese de que a sexualidade é uma construção, o produto de um processo plástico, atravessado por contingências e condicionantes, que está sujeito a desfechos múltiplos e que deixa marcas, pontos de fixação, na vida adulta.

O expediente narrativo de Hoffmann (1817/2015), que faz remontar a crise que eclode no início da vida adulta de Nathanael às suas vivências infantis, quando analisado da perspectiva atual, parece corroborar a tese psicanalítica acerca da etiologia sexual das neuroses. Tal fato torna plausível a hipótese de que a literatura fantástica constituiu um precedente importante para o surgimento da psicanálise.

Salienta-se o quanto é problemático para Freud (1905/1997b) o estabelecimento de um ponto de chegada que sirva de critério para avaliação de uma sexualidade supostamente saudável e normal. Para a psicanálise, o falo encarna a indeterminação e a impossibilidade de delimitar previamente os destinos da sexualidade. Ele é correlato da premissa de que não há conaturalidade na escolha dos parceiros sexuais, independentemente de seus sexos biológicos. O falo exerce uma função de baliza, franqueando uma tomada de posição diante da diferença sexual e da castração, que se evidencia, sobretudo, na impossibilidade de atingir um laço de complementaridade e reciprocidade com o parceiro.

Com efeito, a concepção de sexualidade e de amor sustentada pela psicanálise está em desacordo com o ideal romântico (Loureiro 2000, 2002a) e mais próximo da abordagem fantástica desse tema.

Outro ponto de relevo na apropriação da tradição romântica pela psicanálise é a crítica à razão iluminista clássica, que, na sua origem, sobrepõe consciência, pensamento e razão. O romantismo, sobretudo em sua vertente mais sombria, chamou atenção para a loucura e os estados alterados da consciência - a hipnose, a sugestão e o sonho - como temas estratégicos para tencionar uma concepção essencialista e abstrata de razão.

Seguindo nessa direção, vale a pena se deter um pouco mais no projeto encampado pelos românticos, mas principalmente pela literatura fantástica, que podemos chamar de desmontagem narcísica. Tal empresa se deixa perceber, especialmente, no uso abundante da ironia (Siebers, 1894) e na referência à melancolia (Cantagrel, 2004).

Entende-se que a ironia explora a sobredeterminação e a polifonia dos enunciados para tencionar a pretensão à integridade, homogeneidade e altivez cultivada pelo $\mathrm{Eu}$ (Loureiro, 2002a, 2002b). O dizer irônico pressupõe uma voz outra que é subjetivada - o que quer dizer: assumida como uma produção psíquica legítima -, que levanta contradições e questiona os ideais narcísicos, 
corroborando o reconhecimento de conteúdos, cuja expressão é limitada pela resistência psíquica.

É possível então estabelecer uma correlação entre a tradição literária fantástica e a formulação da estética do infamiliar. O Unheimliche, para a psicanálise, é ao mesmo tempo o mais íntimo e o mais exterior ao sujeito. Ele é a marca de uma alteridade fundadora em seu sentido mais arcaico e primitivo. Para Freud (1919/2019), o infamiliar é o sentimento decorrente da apercepção de um conteúdo psíquico constitutivo e constituinte até então não reconhecido. Tal conteúdo, que se encontrava em estado latente, torna-se subitamente manifesto. Desse modo, o Unheimliche pode ser considerado uma resposta que remonta a um momento em que o Eu principia a se reconhecer como imagem e o campo do outro começa a se definir. Só a partir desse ponto é possível falar de semelhança e diferença. Antes disto, se é refém da univocidade e a linguagem possui o valor do percebido.

$\mathrm{O}$ infamiliar remete a uma experiência que dialetiza, ainda que de modo fugaz, as fronteiras do $\mathrm{Eu}$ e a sensação de familiaridade em relação ao cotidiano. Tal sentimento é acompanhado por uma angústia moderada, cuja modulação é amplamente explorada nos textos fantásticos que serviram de material para a reformulação da teoria freudiana sobre esse tema.

Constata-se então uma íntima relação entre o ensaio do infamiliar (Freud, 1919/2019) e os textos sobre a segunda tópica. Logo o Unheimliche não deve ser considerado uma construção isolada e fortuita na obra freudiana. A fina conexão desse conceito com a literatura Fantástica e o romantismo se deixa verificar a partir das inúmeras referências presentes nos ensaios de Freud e de Rank sobre o infamiliar e o duplo (Rabêlo, Martins, \& Sträter, 2019) a escritores cujas obras situam-se no campo desse território literário e desse movimento cultural. Defende-se que a leitura dessas obras literárias constituiu um recurso importante no percurso de Freud e de seus colaboradores, ao lado da clínica, para a construção de uma teoria do Eu e de suas falhas - isto é, a psicose, a melancolia e o luto (Freud, 1933/1997).

A partir desse argumento, questiona-se a afirmação de Siebers (1984), da qual se reconhece antecedentes no texto de Rank (1914), de que a retórica irônica romântica estaria relacionada à fragilização da situação psíquica do escritor. Em princípio, pode-se objetar que narrador, personagem, escritor e autor são funções distintas, que se enodam, mas não se confundem (Willemart, 2014). No entanto mais importante para o objetivo deste trabalho é assinalar que, para a psicanálise, a categoria de $\mathrm{Eu}$ não se confunde com a totalidade do aparelho psíquico, tampouco representa seu centro de gravidade. Por conseguinte o processo de derrisão narcísica promovido pela ironia romântica não implica necessariamente na fragilização psíquica, seja ela do leitor ou do escritor.

A clínica psicanalítica demonstra que se, por um lado, a manutenção de algum nível de investimento e coesão narcísicos é importante para se alcançar o equilíbrio psíquico, sua inflação, em contrapartida, não é sinônimo de saúde, uma vez que ela leva ao estreitamento dos canais de comunicação entre as instâncias psíquicas e à exacerbação dos conflitos. Logo convém que o Eu seja poroso e permeável aos produtos advindos do Isso (Freud, 1933/1997).

Outro ponto de interesse da relação entre romantismo, literatura fantástica e psicanálise está na valorização da sobredeterminação e dos hiatos da significação (Todorov, 2012). Defende-se que tanto a literatura fantástica quanto a psicanálise podem ser enquadradas entre as modalidades discursivas que Figueiredo (1991) descreve como pós-românticas, nas quais sobressai a indicação de uma insuficiência das representações e de uma não coincidência entre as palavras e as coisas.

Também é relevante destacar a dialetização da relação entre crença e não crença como temática que ganha relevância e complexidade na transição do romantismo para o fantástico, e deste para a psicanálise, quando a problematização da natureza da dúvida ganha uma nova conotação. No romantismo (Mezan, 2013), a dúvida impulsiona a exploração de fenômenos situados nas franjas da razão. No fantástico, ela serve à realização artificial de uma zona de indeterminação e indecisibilidade propícia à eclosão do sentimento do estranho (Todorov, 2012) e do infamiliar. Por fim, na psicanálise, a dúvida é percebida como um fenômeno relacionado à expressão dos processos psíquicos inconscientes (Freud, 1900/1997).

Portugal (2006) discute essa questão a partir da comparação entre: (1) a convicção supersticiosa, que assume a fé em uma causalidade externa sobrenatural; (2) a certeza paranoica, cuja crença é autorreferente e não permite retificação; e (3) a aposta no Inconsciente na psicanálise, em que uma causalidade interna está posta em questão, mas não exclui a materialidade e a determinação na aleatoriedade dos fatores externos.

Sublinha-se ainda o interesse dos três campos citados pelos mitos. Da perspectiva da psicanálise (Freud, 1912-1913/1997), os mitos vêm designar o limite do discurso científico, no qual a relação do sujeito com uma alteridade na sua forma mais radical e intuitiva é colocada em questão. Trata-se do ponto onde as explicações sobre a origem psíquica, social e biológica do ser falante se entrecruzam e sobre o qual não se tem acesso a não ser pela via de uma abstração lógica. Nesse sentido, a abordagem psicanalítica do mito não é nem supersticiosa, nem religiosa, nem científica em sentido estrito.

\section{Considerações finais}

Este trabalhou buscou mapear os complexos vínculos que unem psicanálise, romantismo e fantástico, esclarecendo que este constitui um elo importante e estratégico entre os dois primeiros. Isso não quer dizer que inexistam outros canais importantes de transmissão do legado do romantismo para a psicanálise (Mann, 1991), o 
que se pode verificar por meio das inúmeras citações a J. W. Goethe, H. Heine (1797-1856) e F. Schiller na obra de Freud, mas também pelas referências - explícitas e implícitas - à filosofia de K. W. F. Schlegel (1772-1829), C. C. Carus (1789-1869) e F. Brentano (1838-1917) (Loureiro, 2002a).

Destacou-se que a influência do romantismo e da literatura fantástica na psicanálise não se restringe ao seu momento de fundação. Ela se estende por toda a obra de Freud, evidenciando-se nos momentos de maior inventividade metapsicológica. Apontou-se a discussão em torno do Infamiliar e da segunda tópica como momentos cruciais nos quais essa influência é atualizada, tornando-se acentuadamente mais manifesta.

Sublinhou-se ainda que os elementos oriundos dessa modalidade literária e desse movimento cultural são profundamente transformados pela psicanálise. Trata-se de um processo que ocorreu de forma original e idiossincrática (Figueiredo \& Loureiro, 2018). Por conseguinte, acredita-se que a investigação dos vínculos entre psicanálise e literatura fantástica pode contribuir para um melhor entendimento da apropriação e transformação da herança romântica na obra de Freud.

\section{Echoes of the romanticism and fantastic literature in psychoanalysis}

Abstract: This paper maps the historical, aesthetic, and epistemic processes of the 18th and 19th centuries that associate romanticism, fantastic literature and psychoanalysis. We argue that fantastic is an important vector through which elements of romanticism were incorporated into the psychoanalytic model of the psyche. Assuming that such Romantic influences were assimilated selectively and creatively, we highlight some points of contention and compromise between romanticism and the Enlightenment that were later resumed and transformed by fantastic literature and psychoanalysis: the themes of love, madness, sexuality, superstitions and myths; the relationship between reality and its representations and between thought and consciousness; and the rhetorical use of irony. Finally, the text points to the psychoanalytic approach of the uncanny (Unheimliche) as the most sensitive moment of such exchange.

Keywords: romanticism, fantastic literature, psychoanalysis, Unheimliche.

\section{Les échos du Romantisme et de la Littérature fantastique en psychanalyse}

Résumé : Cet article cartographie les processus historiques, esthétiques et épistémiques des XVIIIle et XIXe siècles qui associent le romantisme, la littérature fantastique et la psychanalyse. On soutient que le fantastique constitue un vecteur important par lequel des éléments du romantisme ont été incorporés dans le modèle psychanalytique de l'appareil psychique. Cette perspective repose sur le fait que l'assimilation de l'influence romantique s'est déroulée de manière sélective et créative. On mit en évidence certains points de tension et de compromis entre le romantisme et les Lumières, repris et transformés par le fantastique et la psychanalyse : les thèmes de l'amour, de la folie, de la sexualité, des superstitions et des mythes ; la remise en cause du rapport entre le réel et ses représentations et entre la pensée et la conscience ; et l'usage rhétorique de l'ironie. On signale l'approche psychanalytique de l'Unheimliche comme le moment le plus sensible de cette interlocution.

Mots-clés : romantisme, littérature fantastique, psychanalyse, Unheimliche.

\section{Resonancias del romanticismo y la literatura fantástica en el psicoanálisis}

Resumen: Se cartografían los procesos históricos, estéticos y epistémicos del siglo XVIII y XIX que asocian el romanticismo, la literatura fantástica y el psicoanálisis. Se argumenta que lo fantástico es un importante vector a través del cual los elementos del romanticismo se han incorporado al modelo psicoanalítico del aparato psíquico. Se entiende que la asimilación de la influencia romántica se produjo de forma selectiva y creativa. Se destacan algunos puntos de tensión y compromiso entre el romanticismo y la ilustración que han sido asumidos y transformados por lo fantástico y el psicoanálisis: los temas del amor, la locura, la sexualidad, las supersticiones y los mitos; el cuestionamiento de la relación entre lo real y sus representaciones y entre pensamiento y conciencia; y la apreciación del uso retórico de la ironía. El enfoque psicoanalítico de lo ominoso (Unheimliche) se señala como el momento más sensible de esta interlocución.

Palabras clave: romanticismo, literatura fantástica, psicoanálisis, Unheimliche. 


\section{Referências}

Batalha, M. C. (2003). A importância de E. T. A. Hoffmann na cena romântica francesa. Alea: Estudos Neolatinos, 5(2), 257-271. doi: 10.1590/S1517-106X2003000200008

Batalha, M. C. (2012). Literatura fantástica: algumas considerações teóricas. Letras \& Letras, 28(2), 481-506.

Calvino, I. (2004). Contos fantásticos do século XIX: o fantástico visionário e o fantástico cotidiano. São Paulo, SP: Companhia das Letras.

Calvino, I. (2006). Definições de territórios: o fantástico. In I. Calvino, Assunto encerrado (pp. 256-259). São Paulo, SP: Companhia das Letras.

Cantagrel, L. (2004). De la maledie à l'ecriture: genèse de la mélancolie romantique. Tübingen: Max Niemeyer.

Carpeaux, O. M. (2014). A história concisa da literatura alemã. São Paulo, SP: Faro Editorial.

Carvalho, B. (1989). O "Unheimlich” em Freud e Schelling. Percurso, 3(1), 17-21.

Casares, A. B. (2013). Prólogo. In J. L. Borges, S. C. Ocampo, \& A. B. Casares (Orgs.), Antologia da literatura fantástica (pp. 9-19). São Paulo, SP: Cosac Naify.

Cattapan, P. (2019). Iluminismo e romantismo na formação psicanalítica. Psicologia Clínica, 31(1), 167-188. doi: 10.33208/pc1980-5438v0031n01a08

Ceserani, R. (1999). Lo fantástico. Madrid: Visor.

Duarte, L. F. D. (2004) A pulsão romântica e as ciências humanas no ocidente. Revista Brasileira de Ciências Sociais, 19(55), 5-18. doi: 10.1590/S0102-69092004000200001

Figueiredo, L. C. M. (2000) Matrizes do pensamento psicológico. Rio de Janeiro, RJ: Vozes.

Figueiredo, L. C. M., \& Loureiro, I. (2018). Os saberes Psi em questão: sobre o conhecimento em Psicologia e Psicanálise. Rio de Janeiro, RJ: Vozes.

Foucault, M. (1978). História da loucura na idade clássica. São Paulo, SP: Perspectiva.

Foucault, M. (1999). As palavras e as coisas: uma arqueologia das ciências humanas. São Paulo, SP: Martins Fontes.

Freud, S. (1997) Psychische Behandlung: seelische Behandlung (Studienausgabe, Vol. Ergänzungsband, pp. 13-36). Frankfurt: S. Fischer. (Trabalho original publicado em 1890)

Freud, S. (1997). Die Traumdeutung (Studienausgabe, Vol. II). Frankfurt: S. Fischer. (Trabalho original publicado em 1900)

Freud, S. (1997). Die Freudsche psychoanalytische Methode (Studienausgabe, Vol. Ergänzungsband). Frankfurt: S. Fischer. (Trabalho original publicado em 1904)

Freud, S. (1997a). Drei Abhandlungen zur Sexualtheorie (Studienausgabe, Vol. V, pp. 37-146). Frankfurt: S. Fischer. (Trabalho original publicado em 1905)

Freud, S. (1997b). Über Psychoterapie (Studienausgabe, Vol. Ergänzungsband). Frankfurt: S. Fischer. (Trabalho original publicado em 1905)

Freud, S. (1997). Totem und Tabu (Einige Übereinstimmungen im Seelenleben der Wilden und der Neurotiker)
(Studienausgabe, Vol. IX, p. 287-444). Frankfurt: S. Fischer. (Trabalho original publicado em 1912-1913)

Freud, S. (1997). Neue Folge der Vorlesungen zur Einführung in die Psychoanalyse - 31. Vorlesung: Die Zerlegung der psycheschen Persönlichkeit. (Studienausgabe, Vol. I, pp. 496-516). Frankfurt: S. Fischer. (Trabalho original publicado em 1933)

Freud, S. (1999). Psychoanalyse und Libidotheorie (Gesammelte Werke, Vol. XIII, pp. 211-233). Frankfurt: S. Fischer. (Trabalho original publicado em 1922)

Freud, S. (1999). Kurzer Abriss der Psychoanalyse (Gesammelte Werke, Vol. XIII, pp. 405-427). Frankfurt: S. Fischer. (Trabalho original publicado em 1924)

Freud, S. (1999). Selbstdarstellung (Gesammelte Werke, Vol. XIV, pp. 31-96). Frankfurt: S. Fischer. (Trabalho original publicado em 1925)

Freud, S. (2019). O Infamiliar/Das Unheimliche. Belo Horizonte, MG: Autêntica. (Trabalho original publicado em 1919)

Gautier, T. (1999). A morta enamorada. In T. Gautier, Contos fantásticos (pp. 59-91). São Paulo, SP: Primeira Linha. (Trabalho original publicado em 1936)

Gay, P. Freud: uma vida para nosso tempo. São Paulo: Companhia das Letras.

Hoffmann, E. T. A. (2015). Der sandmann. In E. T. A. Hoffmann, Das Gesammelte Werke (pp. 189-224). Colônia: Anaconda. (Trabalho original publicado em 1817)

Kierkegaard, S. (1976). Der ironie. Baden-Baden: Suhrkam Taschenbuch Wissenschaft.

Koyré, A. (2006). Do mundo fechado ao universo infinito. Rio de Janeiro, RJ: Forense Universitária.

Loureiro, I. R. B. (2000). A totalidade como ilusão: a concepção freudiana de ciência e o estilo romântico. Ágora, 3(2), 5163. doi: 10.1590/S1516-14982000000200003

Loureiro, I. R. B. (2002a). O carvalho e o pinheiro: Freude $o$ estilo romântico. São Paulo, SP: Escuta.

Loureiro, I. R. B. (2002b). Sobre a noção de "ironia romântica" e sua presença na escrita de Freud. Revista Latinoamericana de Psicopatologia Fundamental, 5(2), 78-91. doi: 10.1590/1415-47142002002006

Löwy, M., \& Sayre, R. (1995). Revolta e melancolia: o romantismo na contramão da modernidade. Petrópolis, RJ: Vozes.

Mann, T. (1991). Freud und die Psychoanalyse: Reden, Briefe, Notizen, Betrachtung. Frankfurt: S. Fischer. (Trabalho original publicado em 1929)

Matangrano, B. A., \& Tavares, E. (2018). Fantástico brasileiro: o insólito literário do romantismo ao fantástico. Curitiba, PA: Arte \& Letra.

Maupassant, G. de. (2015). A morta. In G. de Maupassant, $O$ Horla e outras histórias (pp. 119-125). Porto Alegre, RS: L\&PM. (Trabalho original publicado em 1887)

Mezan, R. (2013). Freud: a trama dos conceitos. São Paulo, SP: Perspectiva. 
Palma, A, Chiarini, A. M., \& Teixeira, M. J. G. (2013). $O$ romantismo europeu: antologia bilíngue. Belo Horizonte, MG: Autêntica.

Poe, E. A. (2006). Ligeia. In E. A. Poe, The complete illustrated works of Edgard Allan Poe (pp. 167-180). London: Bounty Books. (Trabalho original publicado em 1838)

Portugal, A. M. (2006). O vidro da palavra: o estranho, a literatura e a psicanálise. Belo Horizonte, MG: Autêntica.

Rabêlo, F. C., Martins, K. P. H., \& Sträter, T. (2019). As referências literárias em "Das Unheimliche". Revista Latinoamericana de Psicopatologia Fundamental, 22(3), 606-629. doi: 10.1590/1415-4714.2019v22n $3 \mathrm{p} 606.11$

Rancière, J. (2009). O inconsciente estético. São Paulo, SP: Editora 34.

Rank, O. (1914). Der Doppelgänger. Imago: Zeitschrift für Anwendung der Psychoanalyse auf die Geisteswissenschaften, 3(2), 97-164.
Roas, D. (2014). A ameaça do fantástico: aproximações teóricas. São Paulo, SP: Unesp.

Rodrigues, A. S. (2007). Sexualidade e perversão na literatura romântica. Psicologia em Pesquisa, 1(2), 67-85. Recuperado de: http://pepsic.bvsalud.org/pdf/psipesq/ v1n2/v1n2a08.pdf

Siebers, T. (1984). The romantic fantastic. London: Cornell University.

Todorov, T. (2012). Introdução à literatura fantástica. São Paulo, SP: Perspectiva.

Trias, E. (2005). O belo e o sinistro. Lisboa: Fim de Século. Willemart, P. (2014). Psicanálise e teoria literária: o tempo lógico e as rodas da escritura e da leitura. São Paulo, SP: Perspectiva.

Recebido: $17 / 02 / 2020$

Revisado: 03/11/2020

Aprovado: 06/07/2021 